\title{
Discovery of and Mechanistic Insight into a Ligand-Modulated Palladium-Catalyzed Wacker Oxidation of Styrenes Using TBHP
}

\author{
Candace N. Cornell and Matthew S. Sigman* \\ Department of Chemistry, University of Utah, 315 South 1400 East, Salt Lake City, Utah 84112-8500
}

The oxidation of terminal olefins to methyl ketones with Pd(II) complexes, known as the Wacker oxidation, is a well-established synthetic transformation used in the production of acetaldehyde on an industrial scale. ${ }^{1}$ Classically, this reaction requires catalytic Pd-(II) and stoichiometric $\mathrm{CuCl}_{2}$ under aerobic conditions. Chlorinated byproducts and palladium decomposition limit the exploitation of the Wacker oxidation. ${ }^{1 \text { a }}$ Many modifications have been developed allowing for oxidation of more complex targets, but most still utilize the addition of a copper cocatalyst. ${ }^{1 \mathrm{c}}$ Copper additives severely limit the use of ligands with Pd. Ligand modulation of Pd catalysis has proven to be vital in the development of more effective and asymmetric catalysts for the mechanistically related aerobic alcohol oxidation. ${ }^{2}$ Consequently, we were interested in developing a catalytic system for the Wacker oxidation that would alleviate the need for copper additives. ${ }^{3}$ We report herein the discovery and preliminary mechanistic considerations of a promising new $\mathrm{N}$-heterocyclic carbene-modulated $\mathrm{Pd}$ catalyzed Wacker oxidation that uses tert-butylhydroperoxide (TBHP).

The effectiveness of $\mathrm{Pd}(\mathrm{IiPr})(\mathrm{OAc})_{2} \bullet\left(\mathrm{H}_{2} \mathrm{O}\right)(\mathbf{1})$ in aerobic alcohol oxidations led us to test this catalyst for the Wacker oxidation of styrene. Styrene derivatives are generally problematic substrates for these oxidations due to polymerization or oxidative cleavage to benzaldehyde and/or benzoic acid. ${ }^{1 \mathrm{~b}, 4}$ Oxidation of styrene with $2.5 \mathrm{~mol} \% 1$ at $0.3 \mathrm{M}$ in THF leads primarily to acetophenone with $95 \%$ conversion at $24 \mathrm{~h}$ (Figure 1). Monitoring the reaction via in situ FTIR spectroscopy reveals a ca. $10 \mathrm{~h}$ induction period, which was presumed due to the formation of an active catalyst species. ${ }^{5}$ To explore if the active catalyst was cationic in nature, a range of counterions was evaluated. Less basic counterions show a significant decrease in induction period. ${ }^{6}$ Optimization of the reaction solvent illustrated the unusual nature of this oxidation in which THF proved to be the only competent reaction solvent. ${ }^{7}$ Of note, no oxidation was observed in 2,2,5,5-tetramethyl-THF. On further examination of the in situ FTIR data, two other carbonyl stretches were observed and attributed to $\gamma$-butyrolactone and succinic dialdehyde, products of THF oxidation. Additionally, the THF oxidation rate is qualitatively similar to that of the Wacker oxidation.

One plausible explanation of these data is that a cationic Pd complex catalyzes an aerobic oxidation of THF to 2-tetrahydrofuryl hydroperoxide. The peroxide can then act as a reagent or an oxidant in the Wacker process. This type of coupled oxidation has been previously observed by Alper and co-workers. ${ }^{4 \mathrm{c}}$ To test if a peroxide is involved in the catalysis, styrene was submitted to catalytic $\mathrm{Pd}$-(IiPr)(OTs $)_{2}$ and 5 equiv of TBHP in toluene under anaerobic conditions. Complete conversion of styrene to $>97 \%$ acetophenone was observed without an induction period. This is especially noteworthy since other Wacker oxidations of styrenes, which do not utilize a ligand on Pd, lead to considerable levels of oxidative cleavage. ${ }^{4}$

(c) 2005 American Chemical Society

E-mail: E-mail: sigman@chem.utah.edu. 
Optimization led to the following conditions: $0.75 \mathrm{~mol} \%$ [Pd-(IiPr) $\left.\mathrm{Cl}_{2}\right]_{2}$ (2), $3.2 \mathrm{~mol} \%$ AgOTf, 5.5 equiv of $\mathrm{TBHP}_{(\mathrm{aq})}$, and $0.5 \mathrm{M}$ substrate in $\mathrm{MeOH}$ at $35^{\circ} \mathrm{C}^{8}$ Several styrene derivatives were tested to explore the initial scope of this method (Table 1). High selectivity for the oxidation of primary aryl olefins to ketones ( $>95 \%)$ is demonstrated with minimal observed aldehyde formation. Different substitution patterns on the aryl ring lead to similar yields (entries 2 and 3 ). A sterically hindered olefin converts more slowly to the methyl ketone but, again successful oxidation is observed (entry 5). Electronics play a minimal role where 3nitrostyrene only requires a slight increase in catalyst loading for competent oxidation (entry 7). The high versatility of the system is showcased where trans-stilbene, an internal olefin, is oxidized in an aprotic, nonpolar solvent though significant levels of oxidative cleavage to benzaldehyde are observed (entry 8).., 10

A question this system provokes is, why are peroxides needed for this transformation while a related catalyst utilizes $\mathrm{O}_{2}$ for alcohol oxidation? To begin probing this question, mechanistic studies were undertaken. Kinetic studies reveal an overall zero-order reaction with a first-order dependence on $\left[\mathrm{Pd}(\mathrm{IiPr})(\mathrm{OTf})_{2}\right](0.3-6.0 \mathrm{~mol} \%)$ and a zero-order dependence on both [styrene] (0.3-0.9 M) and [TBHP] (3-12 equiv). ${ }^{11}$ Use of anhydrous TBHP in $\mathrm{MeOH}^{12}$ led to an inverse first-order dependence on $\left[\mathrm{H}_{2} \mathrm{O}\right](0.5-12 \mathrm{M})$. The resulting empirical rate law supports rate-limiting dissociation of water from a palladium catalyst. ${ }^{13}$ The X-ray crystallographic analysis of $\mathrm{Pd}(\mathrm{IiPr})(\mathrm{OTf})_{2}$ of the ground-state structure shows dative bonds from three molecules of water to Pd (Figure 2). This supports a mechanism wherein water dissociation is necessary prior to substrate binding.

Considering direct kinetic evidence for nucleopalladation is not feasible, isotopic labeling studies were used to probe the nature of the nucleophile and subsequent decomposition to acetophenone. Two limiting mechanistic scenarios have been proposed for this transformation: addition of water to the olefin followed by a $\beta$-hydride elimination-type process or the mechanism originally proposed by Mimoun, ${ }^{14}$ wherein formation of a palladacycle via insertion of the olefin into a peroxo-Pd species is followed by a 1,2-hydride shift-type mechanism (Scheme 1). The palladacycle mechanistic scenario has been used to account for the observed formation of oxidatively cleaved products in the Wacker oxidation of styrenes. ${ }^{4 \mathrm{c}}$ Previous isotopic labeling studies of ethylene oxidation under classic Wacker conditions also support Mimoun's 1,2-hydride shift proposal. ${ }^{1 \mathrm{a}}$

To determine if TBHP or $\mathrm{H}_{2} \mathrm{O}$ is the oxygen source in the carbonyl, the Wacker oxidation of styrene using 1.1 equiv of ${ }^{18} \mathrm{OH}_{2}$ under otherwise anhydrous conditions was examined. Only $20 \%{ }^{18} \mathrm{O}$ incorporation at $15 \mathrm{~m}$ (1.3\% product) is observed, which is consistent with TBHP as the primary oxygen source in aceto-phenone. Incomplete ${ }^{16} \mathrm{O}$ incorporation can be attributed to the fast rate of isotopic washing under the reaction conditions. ${ }^{15}$

To determine if a 1,2-hydride shift mechanism is plausible, $\alpha$-D-styrene (>95\% $\alpha$-D) was submitted to the Wacker oxidation. Utilizing $2.0 \mathrm{~mol} \% \mathrm{Pd}(\mathrm{IiPr})(\mathrm{OTf})_{2}$ afforded $81 \%$ incorporation of the deuterium label. This showcases that the dominant pathway conserves the hydrogens and is consistent with a 1,2-hydride shift mechanism wherein an enol is not formed. Furthermore, a double labeling experiment was performed with ${ }^{18} \mathrm{OH}_{2}$ and $\alpha$-D-styrene. The results of this experiment are similar to the individual labeling studies and confirm two parallel pathways for decomposition that are insensitive to the nature of the nucleophile. ${ }^{15}$ It is important to note that a hydride shift mechanism need not proceed via $\operatorname{Pd}(0)$, thus avoiding the common decomposition pathways associated with related processes.

Overall, we have discovered a Pd-catalyzed ligand-modulated Wacker oxidation of styrene derivatives, including internal olefins, using mild conditions with a simple oxidant. Isotopic labeling experiments support a dominant pathway wherein TBHP acts as the oxygen source in 
the addition to the olefin followed by a hydride shift process wherein the protons on styrene are incorporated into product. On the basis of these findings, we are currently considering new approaches to Pd-catalyzed olefin functionalization reactions that do not rely on $\beta$-hydride elimination processes.

\section{Acknowledgment}

This work was supported by the NIH (NIGMS-GM63540). Pd salts were a gift from Johnson Matthey. Atta Arif performed the X-ray crystallographic analysis. M.S.S. thanks the Dreyfus foundation and Pfizer for their support.

\section{References}

1. (a)Smidt J. Chem. Ind 1962:54-62.62(b)Tsuji J. Synthesis 1984;5:369-384.384Acetophenone yield = 63\%. (c) For a recent review, see: (c)Takacs JM, Jiang X-T. Curr. Org. Chem 2003;7:369-396.396

2. (a) Stahl SS. Angew. Chem., Int. Ed 2004;33:3400-3420. (b) Mueller JA, Goller CP, Sigman MS. J. Am. Chem. Soc 2004;126:9724-9734. [PubMed: 15291576]

3. (a) Nishimura T, Kakiuchi N, Onoue T, Ohe K, Uemura S. J. Chem. Soc., Perkin Trans. 1 2000;12:1915-1918. (b) ten Brink GJ, Arends IW, Papdogianakis G, Sheldon RA. Chem. Commun 1998;21:2359-2360.

4. For an example using ionic liquids at high pressure, see:(a)Namboodiri VV, Varma RS, SahleDemessie E, Pillai UR. Green Chem 2002;4:170-173.173Acetophenone yield =79\%. Using surfactants, see:(b)Alandis N, Rico-Lattes I, Lattes A. New J. Chem 1994;18:1147-1149.1149Yield $=83 \%$. Using TBHP, see: (c)Sommovigo M, Alper H. J. Mol. Catal 1994;88:151-158.158Yield = $30 \%$. Using $\mathrm{H}_{2} \mathrm{O}_{2}$ and phase-transfer catalysis, see:(d)Barak G, Sasson Y. J. Chem. Soc., Chem. Commun 1987:1266-1267.1267Yield $=56 \%$.

5. Uozumi Y, Kato K, Hayashi T. J. Org. Chem 1998;63:5071-5075.

6. In situ formation of cationic palladium with $1.5 \mathrm{~mol} \%\left[\mathrm{Pd}(\mathrm{IiPr}) \mathrm{Cl}_{2}\right]_{2}+6 \mathrm{~mol} \% \mathrm{AgX}, 0.3 \mathrm{M}$ in $\mathrm{MeOH}$ at $55^{\circ} \mathrm{C}$, balloon pressure of $\mathrm{O}_{2} \cdot \mathrm{X}^{-}=\mathrm{BF}_{4}$, OTs, OTf leads to $>99 \%$ conversion of styrene in $24 \mathrm{~h}$ via $\mathrm{GC}$, decreasing the induction to $<2 \mathrm{~h}$.

7. Solvents screened include THF, DME, $\mathrm{CH}_{3} \mathrm{CN}$, DMF, 2-butanone, $t \mathrm{BuOH}, \mathrm{PhCF}_{3}$, and 2,2,5,5tetramethyltetrahydrofuran.

8. $\mathrm{H}_{2} \mathrm{O}_{2(\mathrm{aq})}$ as a peroxide source resulted in poor product selectivity and high levels of Pd decomposition. 9. Internal olefins often cannot be oxidized under standard $\mathrm{PdCl}_{2} / \mathrm{CuCl}_{2}$ Wacker conditions (see ref 1). 10. Similar ratios of methyl ketone to oxidative cleavage are seen for styrene under these conditions.

11. To avoid catalyst decomposition, $\omega$ equiv of TBHP are necessary.

12. Sharpless KB, Verhoeven TR. Aldrichimica Acta 1979;12:63-71.

13. Rate $=k_{\text {obs }}[$ catalyst $]\left[\mathrm{H}_{2} \mathrm{O}\right]^{-1}[\text { substrate }]^{0}[\mathrm{TBHP}]^{0}$.

14. (a) Mimoun H, Charpentier R, Mitschler A, Fischer J, Weiss R. J. Am. Chem. Soc 1980;102:10471054. (b) Roussel M, Mimoun H. J. Org. Chem 1980;45:5387-5390.

15. See Supporting Information for details. 


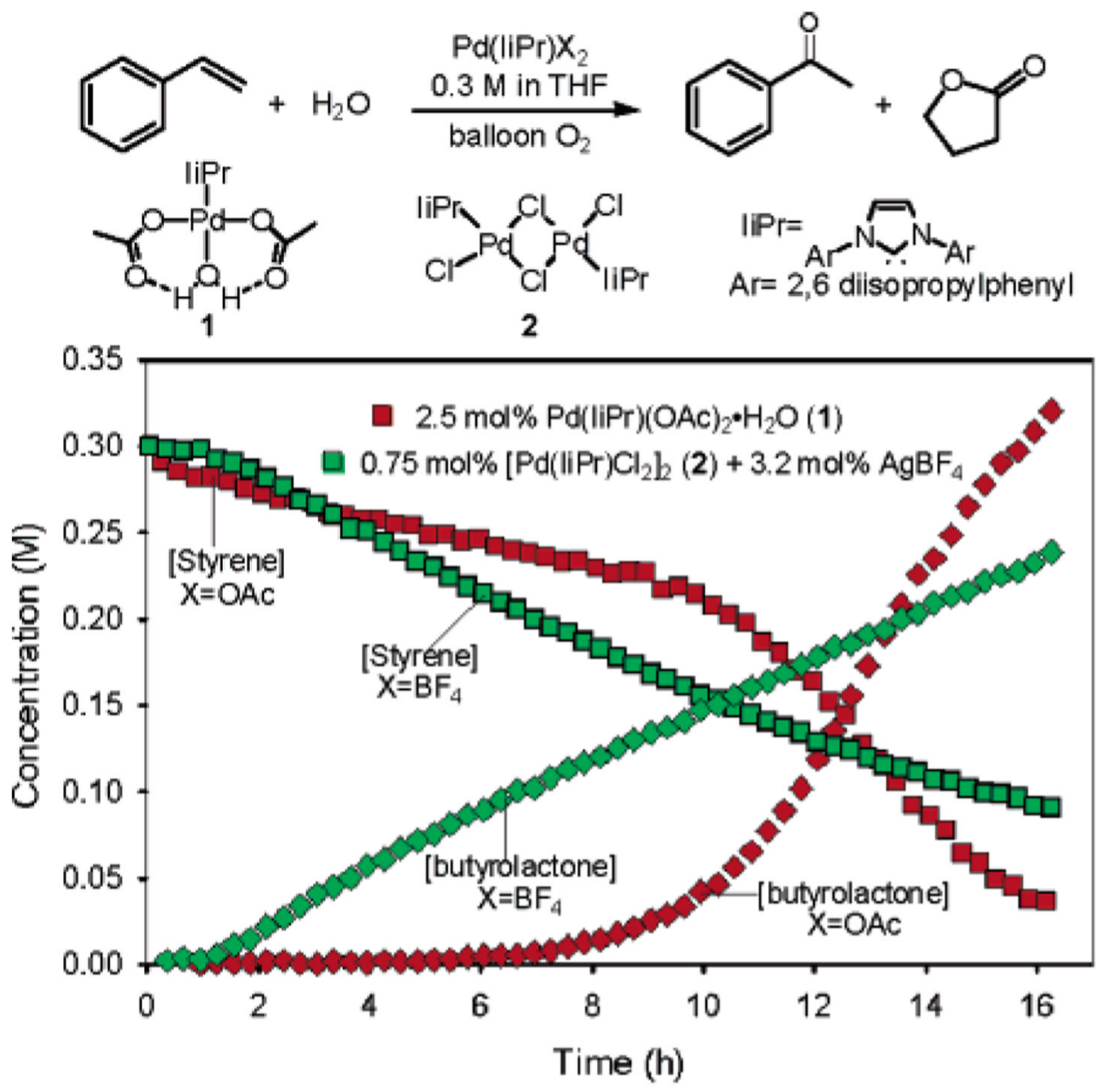

Figure 1.

In situ FTIR monitoring the disappearance of styrene via $\mathrm{C}-\mathrm{H}$ out of plane deformation at $702.9 \mathrm{~cm}^{-1}$ and formation of $\gamma$-butyrolactone via the $\mathrm{CO}$ stretch at $1779.5 \mathrm{~cm}^{-1}$. 


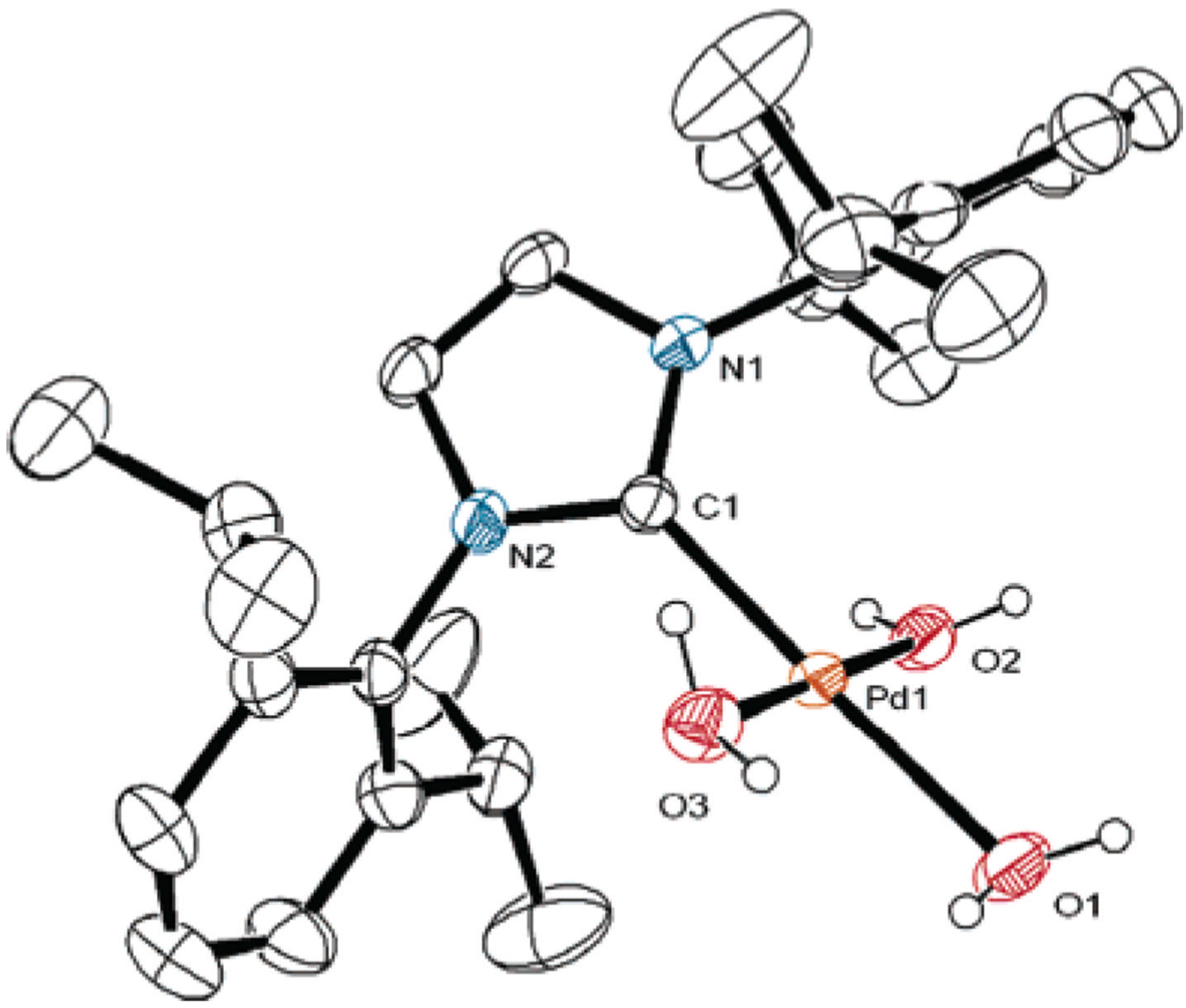

Figure 2.

X-ray crystal structure of $\mathrm{Pd}(\mathrm{IiPr})\left(\mathrm{OH}_{2}\right)_{3} \bullet(\mathrm{OTf})_{2} \bullet\left(\mathrm{H}_{2} \mathrm{O}\right)_{2}$. Two OTf counterions and two $\mathrm{H}_{2} \mathrm{O}$ molecules are excluded for clarity. 


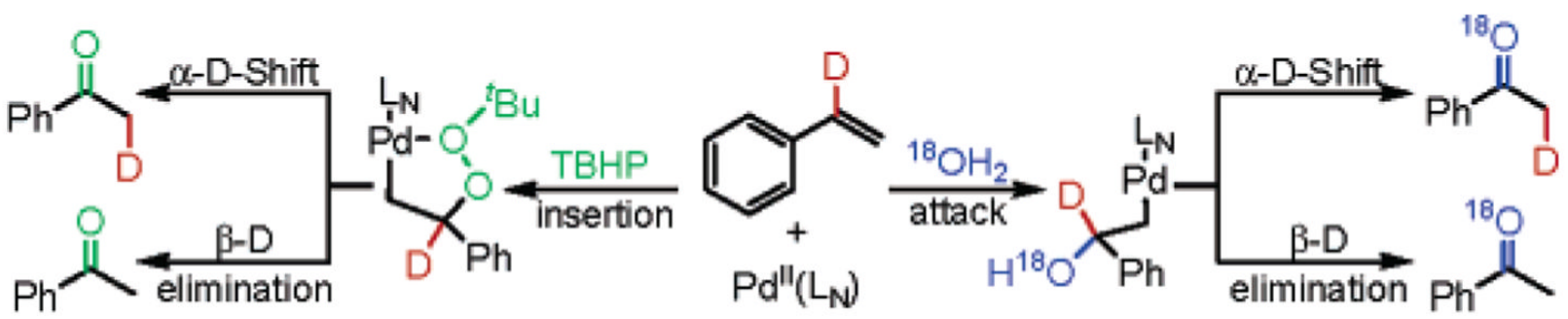

Scheme 1.

Commonly Proposed Mechanistic Pathways for Olefin Oxidation 


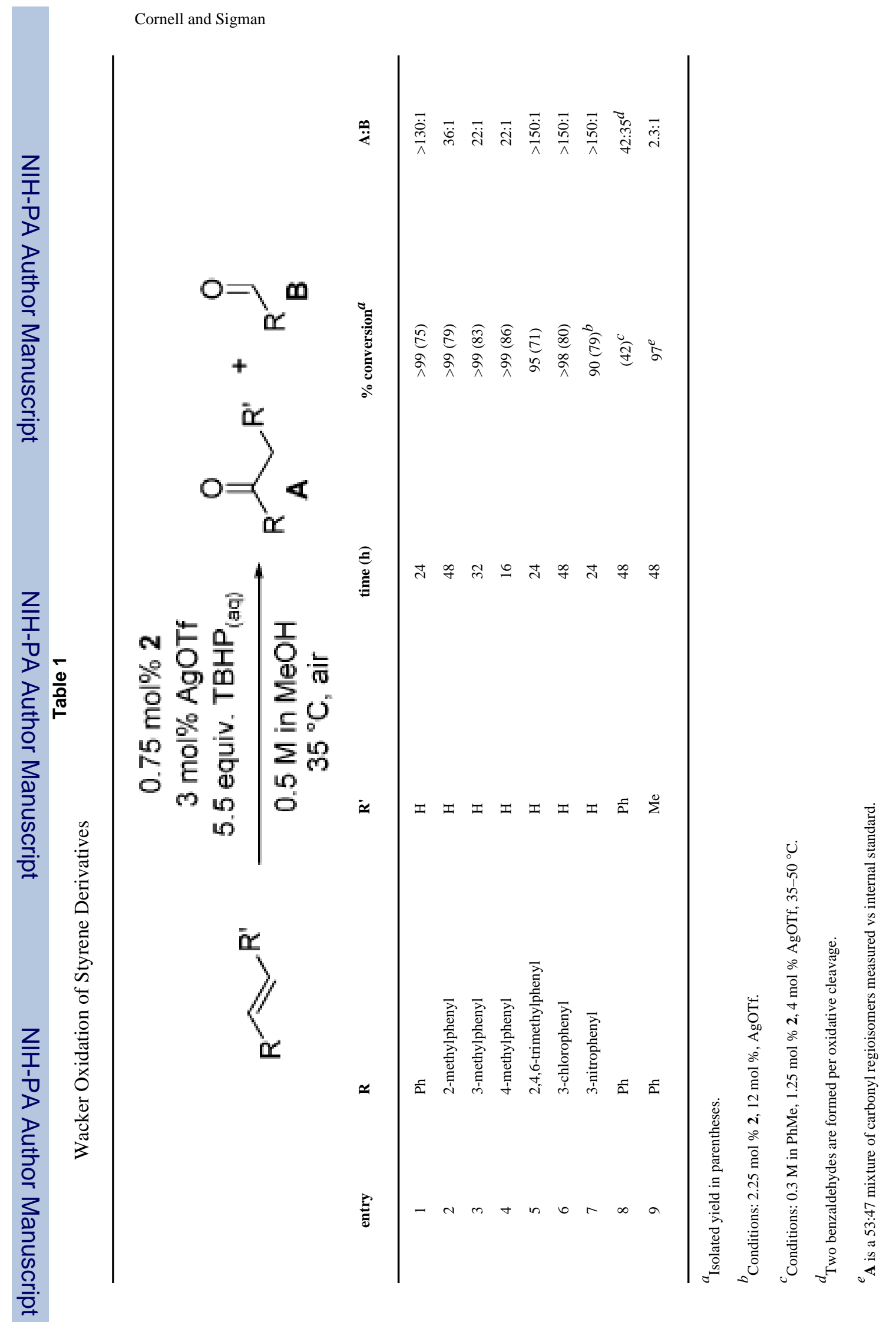

Page 7 